\title{
Seasonal and Solar Cycle Variation of Schumann Resonance Intensity and Frequency at Eskdalemuir Observatory, UK
}

\author{
M.A. Musur ${ }^{1{ }^{*}}$ and C.D. Beggan ${ }^{1}$ \\ ${ }^{1}$ British Geological Survey, Edinburgh, United Kingdom \\ ${ }^{*}$ Visiting scientist \\ E mail (ciar@bgs.ac.uk).
}

Accepted : 30 September 2019

\begin{abstract}
The Schumann resonances are an electromagnetic phenomenon detectable in the Extremely Low Frequency waveband using a search coil magnetometer. They are created by the continuous discharge of lightning globally. The variation of the intensity and frequency of the resonances can generally be related to (a) the diurnal changes in location and intensity of the global lightning centres, (b) the conductivity properties of the ionosphere and (c) general changes in global temperatures. We have collected and analysed seven years of data (from 2012 to 2019) using two horizontal highfrequency magnetometers installed at Eskdalemuir Geomagnetic Observatory in the UK. The site is magnetically quiet and offers an excellent location to monitor the variation of the Schumann resonances in the 1-50 Hz frequency band. We analyse the variation of the first three Schumann resonances to illustrate the quality of the data and confirm many of the previously observed seasonal variations at other sites globally. We see a long-term decline in the frequencies of each resonance, and evidence for a similar change in the intensity over the seven-year period.
\end{abstract}

(C) 2019 BBSCS RN SWS. All rights reserved

Keywords: Schumann resonances; seasonal variation; solar cycle variation

\section{INTRODUCTION}

The Schumann resonances (SR) are electromagnetic (EM) oscillations, with wavelengths approximately divisible by the Earth's circumference, that occur within the Earth-ionosphere cavity. They are excited and sustained by continuous global lightning discharge. The SR are observed below $50 \mathrm{~Hz}$ in the Extremely Low Frequency (ELF) band of the EM spectrum and the first five resonances are found at approximately 8, 14, 20, 27 and $32 \mathrm{~Hz}$, given the natural variability (e.g. Füllekrug, 1995).

Since their prediction by Schumann (1952), many research papers have been published regarding different aspects of Schumann resonances and their applications as monitors for other geophysical variables or systems (e.g., Williams, 1992; Sátori, 1996; Anyamba et al., 2000; Kulak et al., 2003; Greenberg \& Price, 2007; De et al., 2010; Ondrášková et al., 2011; Nickolaenko et al., 2015). For example, Balser \& Wagner (1960) showed the correlation between lightning activity and the diurnal variations in the SR frequencies and amplitudes. Most lightning activity occurs around the equatorial regions when thunderstorms are formed from large convective clouds during the afternoon heat (e.g. Williams et al. 2000; Nieckarz et al., 2009). Diurnal variations in intensity are visible in the SR data and have been found to peak near 08:00, 14:00 and 20:00 UT, which relate to the three main centres of global lightning activity (Asia, Africa and America) when the subsolar point crosses these tropical regions (Sátori, 1996; Price \& Melnikov, 2004; Greenberg \& Price, 2007; Ondrášková et al., 2007).

As noted, e.g. by Nickolaenko et al. (2015), the parameters of SR are also influenced by the properties of the cavity through which they propagate, which includes those of the lower ionosphere. Füllekrug et al. (2002) inferred a global two-scale height ionospheric conductivity profile from the modelled propagation properties of the SR. Williams \& Sátori (2007) used available SR observations to suggest that the SR waveguide is generally insensitive to the changes in the ionizing radiation from the Sun and that order of magnitude changes in radiation are needed to bring noticeable relative changes in the ionospheric height (on diurnal and 11-year timescales). They also noted variations of the SR waveguide height over a range of timescales including diurnal, 27-day solar rotation cycle, annual and an 11year solar cycle (see also Sátori et al. (2005) and Satori et al. (2016))
The diurnal and seasonal variations in peak frequency of the first four SR modes were analysed by Ondrášková et al. (2007) and were ascribed to changes in the intensity and/or positions of the lightning sources as well as changes in the ionosphere heightconductivity profile. Füllekrug \& Fraser-Smith (1996) analysed the amplitudes of the first two SR modes and found 20-30 day variations that they related to the solar rotation cycle (based on the comparison with the sunspot number). The same intensity variations were analysed by Anyamba et al. (2000) who suggested that the SR intensity variations were modified by meteorological variability in the troposphere, rather than by solar rotation.

Zieger \& Sátori (1999) compared long-term periodic variations in SR with solar wind speed and geomagnetic indices (Kp and Dst). Their study found a number of periodicities including 9-10, 13.5, 20, 27, 47, 73 and 108 days with the most significant finding relating to the correlation of half solar-rotation period (13.5 days) within the SR and the geomagnetic activity. While looking into monitoring global thunderstorm activity, Nickolaenko et al. (2015) compared 10 years $(2002-2012)$ of average monthly frequency and intensity data of the first SR mode with corresponding geomagnetic data (intensity of solar radiation at the $10.7 \mathrm{~cm}$ radio wavelength and the Wolf number). Their results show that the SR parameters follow the overall 11-year solar cycle trend suggesting a change in characteristic height of the ionosphere (though see Williams, 2016 for an alternative explanation). During their analysis of the solar variations in the ELF band, Kułak et al. (2003) found indications that the Earthionosphere cavity undergoes long-term conductivity changes during the 11-year solar cycle in the frequency and quality factors (though they did not study the intensity). Sátori et al. (2005) suggested that the variation in solar X-ray emissions can account for the SR intensity changes over the solar cycle.

In 2012, two horizontal induction (search) coil magnetometers were installed at the geophysical observatory in Eskdalemuir (Scottish Borders, UK) operated by the British Geological Survey (BGS). The coils have been recording magnetic field variations over an effective frequency range of $0.1-50 \mathrm{~Hz}$ since September 2012 (Beggan \& Musur, 2018, 2019). Having collected almost seven years of induction coil data, the primary focus of this study is to confirm the properties and characteristics of the SR presented in some of the above cited studies and to illustrate the complex SR seasonal behaviours in a manner not previously shown in the literature. We also carry out this analysis to illustrate the data 
quality from a relatively new station that is not presently wellknown in the SR community.

In Section 2 we describe the instrumentation at Eskdalemuir and the data and methodology used in the study. In Section 3 we analyse the long-term signal in our data using a Fast Fourier Transform (FFT) method, as presented by Nickolaenko et al. (2015), while in Section 4 we produce time-UT plots for the frequency and intensity variations of the first three SR. The results are discussed in Section 5.

\section{INSTRUMENTATION}

For our analysis, we use seven years of ELF geomagnetic data collected using two refurbished CM11E high-frequency induction coil magnetometers (previously used for MT studies). The equipment was deployed in June 2012 in a geomagnetically quiet location at the Eskdalemuir geophysical observatory in the Scottish Borders (UK, $\theta_{\text {geo }}=55.3^{\circ} \mathrm{N}, \Phi_{\text {geo }}=-3.2^{\circ} \mathrm{E}$ ) (see Beggan $\&$ Musur, 2018). The geomagnetic location of the observatory at 2018.0 was $\theta_{\mathrm{gm}}=57.5^{\circ} \mathrm{N}$ in quasi-dipole coordinates with $L \sim$ 3.5. The horizontal coils were set perpendicular to each other, oriented to north-south and east-west relative to geographic North. They are placed above ground on a raised gravel bed and covered by a wooden frame to protect them from wind and rain. They are sited at the edge of the observatory grounds in an open field to reduce manmade interference.

The induction coils measure small rapid magnetic field variations in the ELF band range of $0.1-50 \mathrm{~Hz}$ with a nominal system resolution of $\sim 0.1 \mathrm{pT}\left(10^{-13} \mathrm{~T}\right)$. The analogue output voltage is converted by a 24-bit Guralp digitizer and sent to a logger placed around $150 \mathrm{~m}$ away from the sensor inside a secure vault. The data are sampled at $100 \mathrm{~Hz}$; each second is timestamped using GPS. Every five minutes, the data are automatically collected and permanently stored on the BGS network in Edinburgh. In total, between September 2012 and August 2019 there were around 135 days of data missing due to logging issues or component failure ( $>95 \%$ availability).

The conversion of the raw data to the frequency domain makes use of the Welch periodogram (Welch, 1967). A Butterworth five-pole filter with a $3-40 \mathrm{~Hz}$ bandpass was applied to the raw data from which a series of fast Fourier transforms were computed using the Welch method (with $600 \mathrm{~s}$ of filtered data) to produce 144 1-D periodograms per day. A Hanning window was applied to taper the data $(60,000$ points $)$ prior to the use of a 4,096-point length Fourier transform. Individual periodograms were converted to SI units using the instrument response (around $50 \mathrm{mV} / \mathrm{nT}$ between 0.1 and $100 \mathrm{~Hz}$ for the analogue coils), and digitizer calibration values. The digitizer has a fixed conversion factor of $3.491 \mu \mathrm{V} /$ count for the north-south channel $(\mathrm{CH} 1)$ and $3.475 \mu \mathrm{V} /$ count for the east-west channel $(\mathrm{CH} 2)$, which gives a digitization level of around $0.07 \mathrm{pT} /$ count for both coils for shortperiod signals.

Figure 1 shows example spectrograms (at a higher time resolution using 864 periodograms per day) with the Schumann resonances visible as diffuse vertical bands at around 8, 14, 20, 27, 32 and $38 \mathrm{~Hz}$. The strong peak at $25 \mathrm{~Hz}$ is a subharmonic of the UK electrical power system. The horizontal lines arise from either missing data or spikes for example, from local lightning sources within or close to the UK or from manmade noise, which raises the overall power within a particular 100 -second selection of raw data.

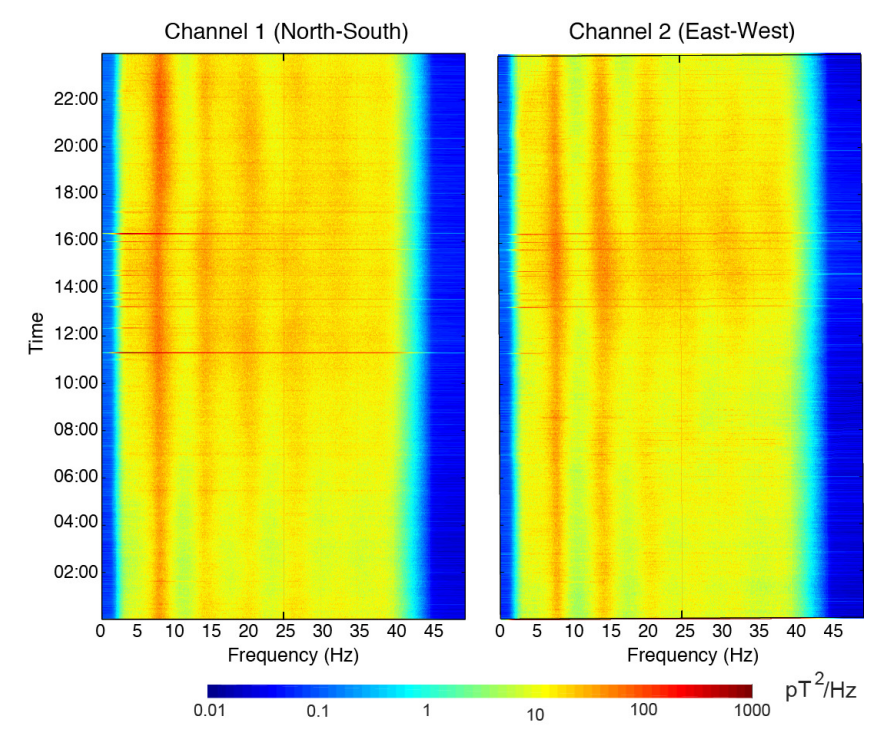

Figure 1. Spectrograms for $22^{\text {nd }}$ September 2012. Left: Channel 1, North-South orientated. Right: Channel 2, East-West orientated. The induction coil data have been band-passed between $3-40 \mathrm{~Hz}$ using a five-pole Butterworth filter. The colour scale goes from blue to red, with the Schumann resonances seen as the diffuse bands at around 8, 14, 20, 27, 33 and $38 \mathrm{~Hz}$.

\section{ANALYSIS OF LONG-TERM SIGNALS}

There are a number of approaches for computing the longterm variation of the resonance parameters. We adapt the method of Nickolaenko et al. (2015) and extend their results from a decade of data from Antarctica beyond 2012. The raw digitiser data were divided into 10-minute intervals and FFT-ed to give 144 periodograms for each day. These were converted to SI units using the system calibration factors.

We computed the average intensities and peak frequencies of the SR modes (denoted by the subscript e.g. 1 for the first SR mode) as follows. Peak frequencies $\left(\mathbf{f}_{1}^{\mathbf{N S}}\left(\mathbf{t}_{\mathbf{i}}\right)\right.$ and $\left.\mathbf{f}_{1}^{\text {EW }}\left(\mathbf{t}_{\mathbf{i}}\right)\right)$ for every 10 -minute time interval $t_{i}, i=1 \ldots 144$ were calculated as a weighted average using the equation:

$$
\mathbf{f}_{1}^{\mathrm{NS}, \mathrm{EW}}\left(\mathbf{t}_{i}\right)=\Sigma_{\mathbf{f}_{0}-\Delta \mathbf{f}}^{\mathbf{f}_{0}+\Delta \mathbf{f}} \mathbf{f} \cdot \mathbf{S}^{\mathrm{NS}, \mathbf{E W}}\left(\mathbf{f}, \mathbf{t}_{i}\right) / \Sigma_{\mathbf{f}_{0}-\Delta \mathbf{f}}^{\mathbf{f}_{0}+\Delta \mathbf{f}} \mathbf{S}^{\mathrm{NS}, \mathbf{E W}}\left(\mathbf{f}, \mathbf{t}_{i}\right)
$$

Where $\mathrm{S}^{\mathrm{NS}}\left(\mathrm{f}, \mathrm{t}_{\mathrm{i}}\right)$ and $\mathrm{S}^{\mathrm{EW}}\left(\mathrm{f}, \mathrm{t}_{\mathrm{i}}\right)$ are power spectra calculated for the separate north-south (NS) and east-west (EW) channels. The first SR mode frequency used by Nickolaenko et al. (2015) was $\mathrm{f}_{0}=8.0 \mathrm{~Hz}$ and $\Delta \mathrm{f}=1.5 \mathrm{~Hz}$, giving a range of $6.5 \mathrm{~Hz} \div 9.5 \mathrm{~Hz}$. For $\mathrm{SR} 2$, we set $\mathrm{f}_{0}$ to $14.0 \mathrm{~Hz}$, and the SR3 $\mathrm{f}_{0}$ value was $21.0 \mathrm{~Hz}$, both with $\Delta \mathrm{f}=1.5 \mathrm{~Hz}$. The intensity was calculated as the value of spectra at each SR peak frequency e.g. for SR1:

$$
\mathbf{I}_{1}^{\mathrm{NS}, \mathbf{E W}}\left(\mathbf{t}_{\mathbf{i}}\right)=\mathbf{S}^{\mathrm{NS}, \mathrm{EW}}\left(\mathbf{f}_{1}^{\mathrm{NS}, \mathrm{EW}}, \mathbf{t}_{\mathbf{i}}\right)
$$

As the FFT spectrum is discrete, we linearly interpolate the intensity to the computed peak frequency value. Daily averaged values of peak frequencies $\mathbf{f}_{1}^{\text {NS,EW }}=\left\langle\mathbf{f}_{1}^{\text {NS,EW }}\left(\mathbf{t}_{\mathbf{i}}\right)\right\rangle$ and intensities $\mathbf{I}_{1}^{\text {NS,EW }}=\left\langle\mathbf{I}_{1}^{\text {NS,EW }}\left(\mathbf{t}_{\mathbf{i}}\right)\right\rangle$, were then computed from September 2012 to August 2019. Finally, a single value per month for each parameter was computed from the mean of the daily values. Due to missing or bad data (e.g. from local man-made sources), four months with anomalous intensity values have been removed from the final result.

Figure 2 contains the results of our analysis, showing the computed monthly values from September 2012 to August 2019. Figure 2a depicts the average monthly intensities for Channel 1 and Channel 2 combined ( $\mathrm{I}=\mathrm{I}_{\mathrm{NS}}+\mathrm{I}_{\mathrm{EW}}$ ). The normalized intensity (by the largest value in the time-series) of the combined channels 
for the first three Schumann resonances are shown by black, red and blue lines, respectively. As can be observed, there is a strong annual variation in intensity, with a minimum during winter and a maximum in summer. In agreement with Nickolaenko et al. (2015) we observe a clear reduction in the intensity over the declining phase of the solar cycle from 2014 to 2019 (Figure 2e). All three resonances show similar behaviour across the period.

The variations of the peak frequency of the first three SR are shown in Figure 2b, 2c and 2d, respectively. The first resonance (Figure 2b) shows the highest values $(>8 \mathrm{~Hz})$ in winter and lowest $(<7.9 \mathrm{~Hz})$ in summer time. Both coils show the same pattern across 2012 to 2019 and there is an overall decline in peak frequency is visible from 2016 onwards. The second resonance (Figure 2c) demonstrates swapping of the peak frequency between the NS and EW coils, with the NS coil being higher in summer than the EW coil but lower in winter. The plot also has a slight decline in peak frequency from 2016 onwards.

For the third SR (Figure 2d), the EW coil has the higher peak frequency, in general, from 2012 to 2019 compared to the NS coil. Figure 2e shows the sunspot number and F10.7 index, which are proxies for solar activity.

Normalized Average Intensity

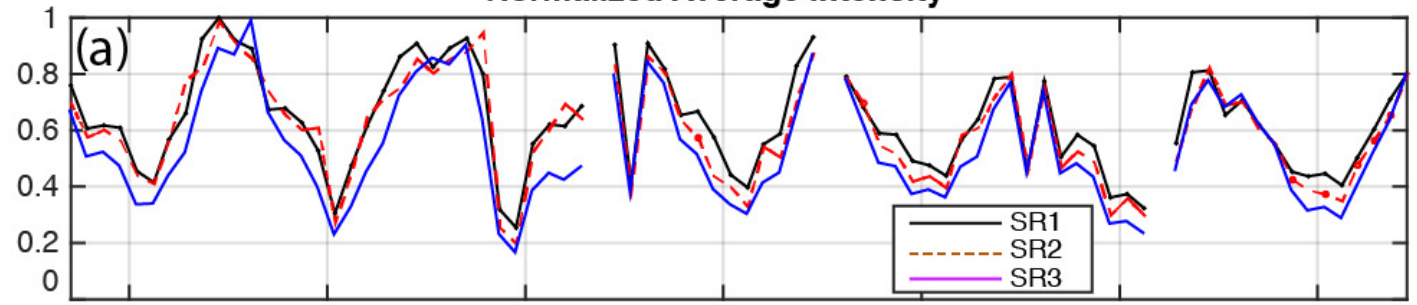

Average Peak Frequencies for the 1st Schumann Resonance

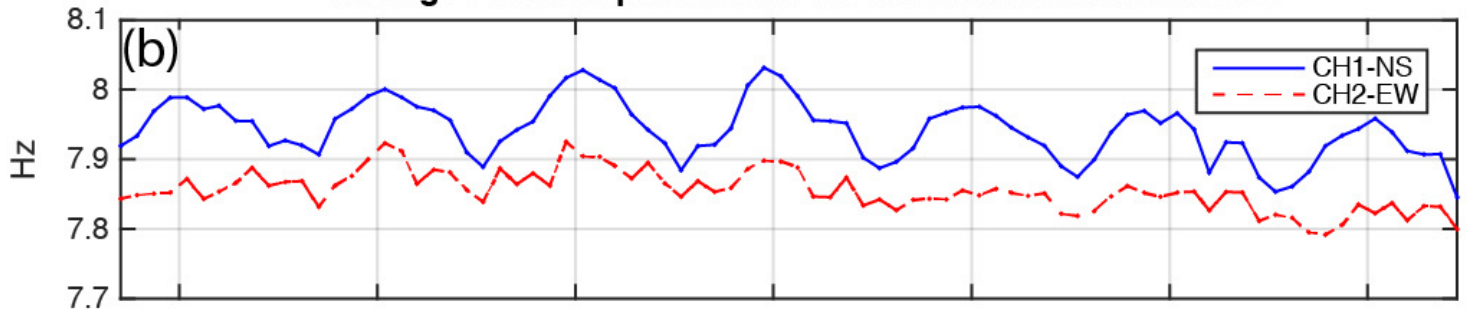

Average Peak Frequencies for the 2nd Schumann Resonance

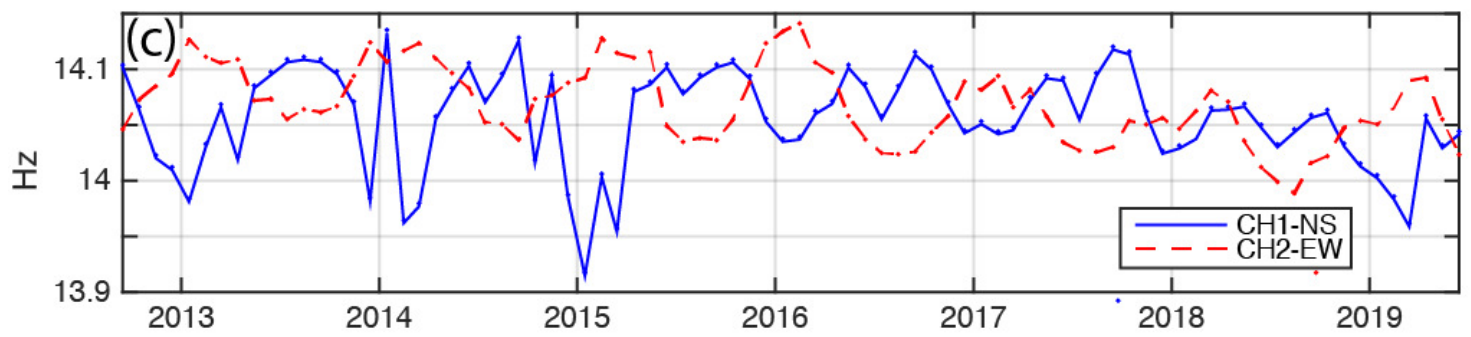

Average Peak Frequencies for the 3rd Schumann Resonance
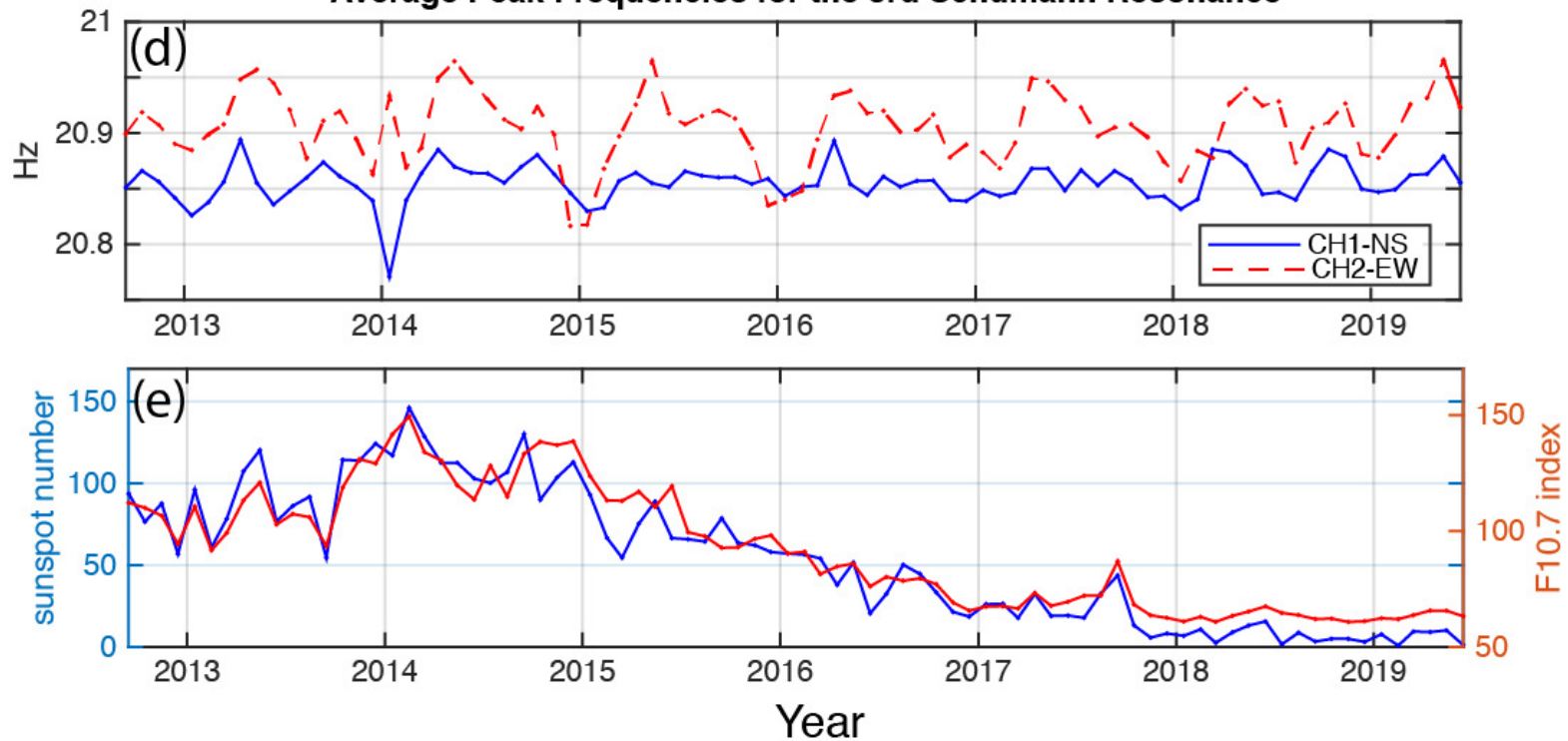

Figure 2. Long-term variations of the Schumann resonances from Sep 2012 to August 2019. (a) Normalized intensity of the first three SR modes observed in the horizontal magnetic field. (b, c, d) Average peak frequencies for the first three SR modes in the North-South channel 1 (CH1-NS) (solid) and East-West channel 2 (CH2-EW) (dashed). (e) Monthly sunspot number and intensity of solar radiation at $10.7 \mathrm{~cm}$ wavelength. 


\section{ANALYSIS OF THE SEASONAL SIGNAL VARIATION}

The gross seasonal variation of the SR parameters (Figure 2) matches the expected (and well-known) variations across the year, with Northern Hemisphere summer showing stronger intensities compared to winter. Williams et al. (2000) noted the annual cycle is strongly influenced by the hemispheric ocean-land asymmetry, based on analysis of the TRMM satellite data (see also Christian et al, 2003). Recent work by Williams et al. (2019) has shown the influence of global temperature changes in the analysis of lightning data from optical measurements.

Rather than averaging over an entire month, it is possible to visualize the daily average of the intensities and frequencies for each resonance and each coil in a Time-Universal Time (UT) plot. We therefore plotted the 10-minute average values for each day as a Time-UT graph for an entire year, with the days of the year (DOY) on the vertical axis and universal time on the horizontal axis. We reduced the inter-annual variation by further averaging over six full calendar years (2013-2018) of data. Figures 3, 4 and 5 show the averaged intensity and frequency variations of first three Schumann Resonances as Time-UT plots observed at Eskdalemuir.

The upper panels of Figure $3(\mathrm{a}, \mathrm{c})$ show the intensity variations of the first Schumann resonance (SR1) in North-South (NS) and East-West (EW) orientated coils. The north-south coil is most sensitive to the Indian and Central-American lightning centres (at 10:00 UT and 20:00 UT, respectively) while the eastwest coil responds to the African centre at 16:00 UT. Both coils have the greatest intensities in Northern Hemisphere summer, as expected. The frequency plot for the NS coil (panel b) shows the lowest values $(<7.9 \mathrm{~Hz})$ around 14:00-16:00 UT in summer. In contrast the EW coil experiences its highest values $(>7.9 \mathrm{~Hz})$ at a similar UT, peaking in winter. The frequency response is related to source receiver distance (e.g. Sátori, 1996). Thus, for the EW coil (panel d), the African centre is closest in summer (giving lower values of mean frequency) while in winter it is further south (leading to higher frequencies). A similar argument applies to the pattern in NS coil (panel b).

The second Schumann resonance (Figure 4) displays similar intensity patterns to the first resonance. The NS coil (panel a) shows a broad and strong lightning centre signal around 10:0016:00 UT compared to the American centre later in the day. The EW coil (panel c) has a noticeable African lightning centre response at 16:00-19:00 UT and also a weak response around 07:00-10:00 UT which may relate to the lightning storms in the Pacific region on the opposite side of the globe at this local time. The frequency plots are again similar to Figure 3 (b and d) but with slightly more complexity and nuance. The NS coil shows a trimodal set of peaks in midsummer, at 06:00, 12:00 and 20:00 UT while the EW coil has a much more distinct and broad American/Pacific centre signal (20:00-06:00 UT) with minimal values in summer.

The response of the third Schumann resonance is shown in Figure 5. The intensity plots (panel a and c) are again broadly similar to the first and second resonances with the summer peaks and response to the same lightning centres. The NS coil has a splitting of the Indonesian centre between 10:00 and 14:00 into two separate smaller peaks in winter which coalesce to a single broad peak in summer time. The American centre has a slight displacement in peak time between winter and summer, as well as a change in intensity. In the EW coil, the African centre has less energy compared to the first resonance and also shows a displacement in the peak time between winter (14:00) and summer (17:00). This is related to the difference in the range of continental longitude extent between the northern and southern hemispheres.

The frequency variation in the third resonance is most intriguing. The NS coil (panel b) shows complex behaviour, with a variable number of peaks throughout the year. During winter there are three broad, though weak, peaks, the most prominent being at 18:00. By the spring equinox (DOY 80), there is one wide indistinct peak which subsequently rapidly bifurcates into five strands. At the autumn equinox (DOY 260) the 14:00 UT and 18:00 UT peaks converge and become a single peak. A 10:00 UT peak forms at spring equinox but fades away by autumn. Conversely, the 02:00 peak is strongest over winter but weakens during summer. This may relate to enhanced sensitivity to the land-sea variation along the latitude of the Tropic of Cancer.

The EW coil frequency (panel d) is somewhat less complicated than the NS coil showing two broad peaks at 12:0018:00 UT and 00:00-06:00 with seasonal variation strongest between the spring and autumn equinoxes. We also note a shortlived feature appears between DOY 100 and 200 around 09:00 UT.
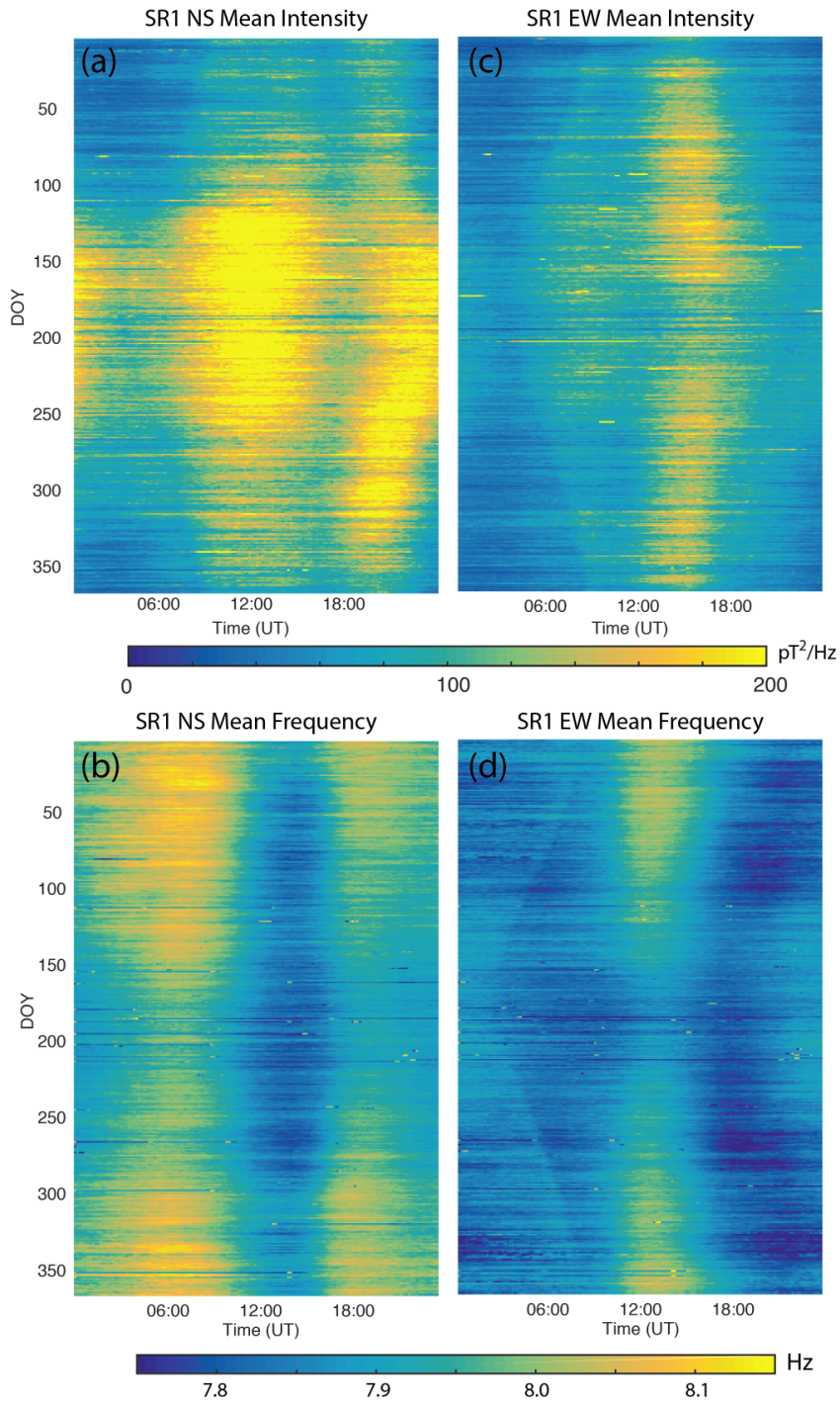

Figure 3. Time-Universal Time plots of the average of six years of the intensity and the peak frequency for the first Schumann resonance (SR1) from the north-south coil $(a, b)$ and the eastwest coil (c, d). 

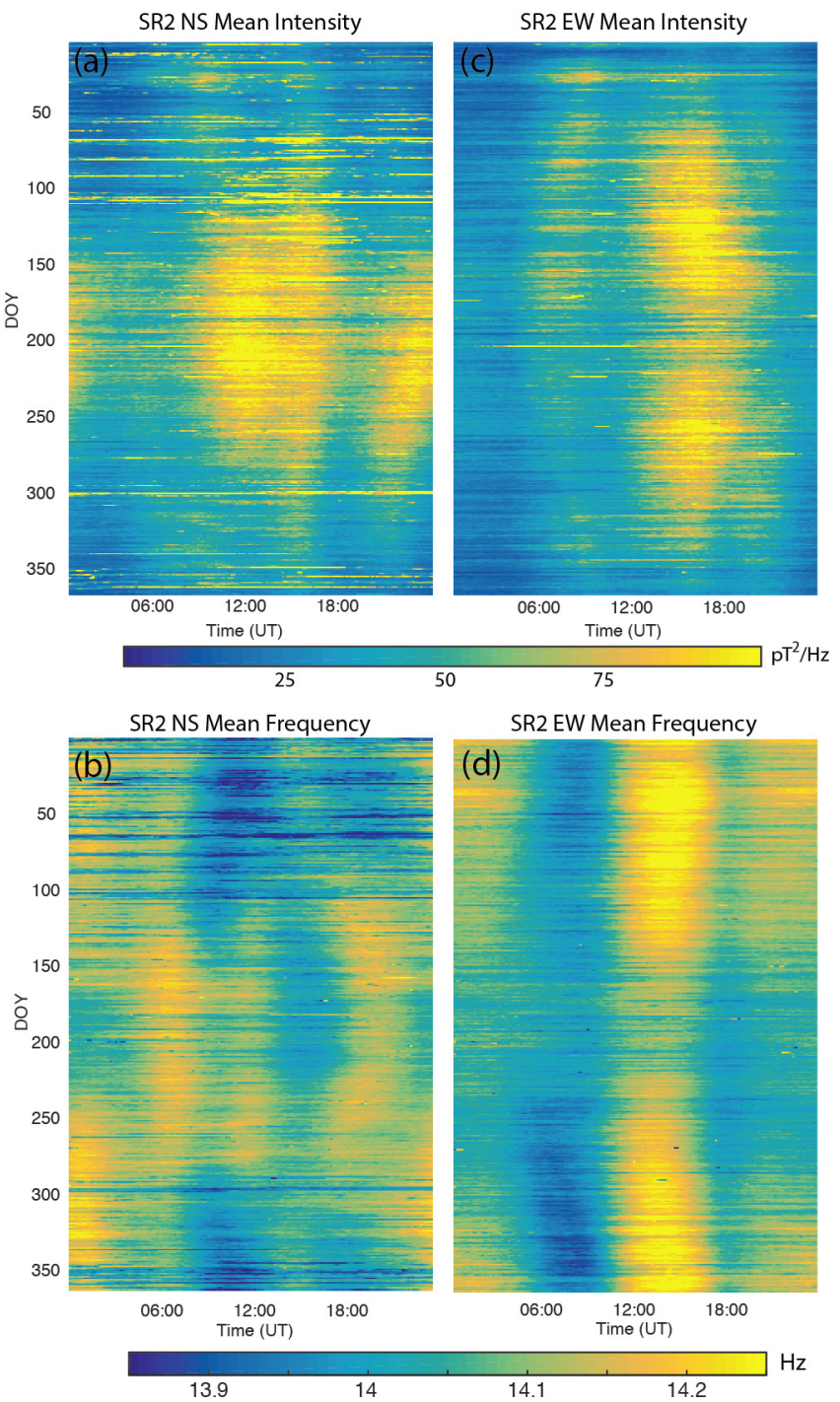

Figure 4. Time-Universal Time plots of the average of six years of the intensity and the peak frequency of the second Schumann resonance (SR2) from the north-south coil $(a, b)$ and the eastwest coil (c, d).

\section{DISCUSSION}

The results in Figure 2 show clear inter-seasonal variability in the SR parameters. We observe that the average intensity values peak during Northern Hemisphere summer months as expected. The seasonal trends in the intensity parameter correspond well with the results reported by Nickolaenko et al. (2015) with a strong correlation with the solar cycle, as observed in their work. The recent rise in global temperature may account for the subdued diminution of the intensities over the present solar cycle (around $20 \%$ ) compared to the decrease in the previous cycle of around $30 \%$ in Nickolaenko et al. (2015).

The frequency parameters of the first and second resonances also show a slight reduction of the peak frequency values with subsiding solar activity, though it is difficult to distinguish in the third resonance. The frequency of the first SR is highest in summer, as is the third SR. The second SR has an alternating pattern with each direction swapping over between summer and winter maxima. Nickolaenko et al. (2015) observe the first SR frequency to be highest in Southern Hemisphere summer, based on data collected from Antarctica, suggesting a hemispheric effect arising from the variation in source-receiver distance throughout the year.
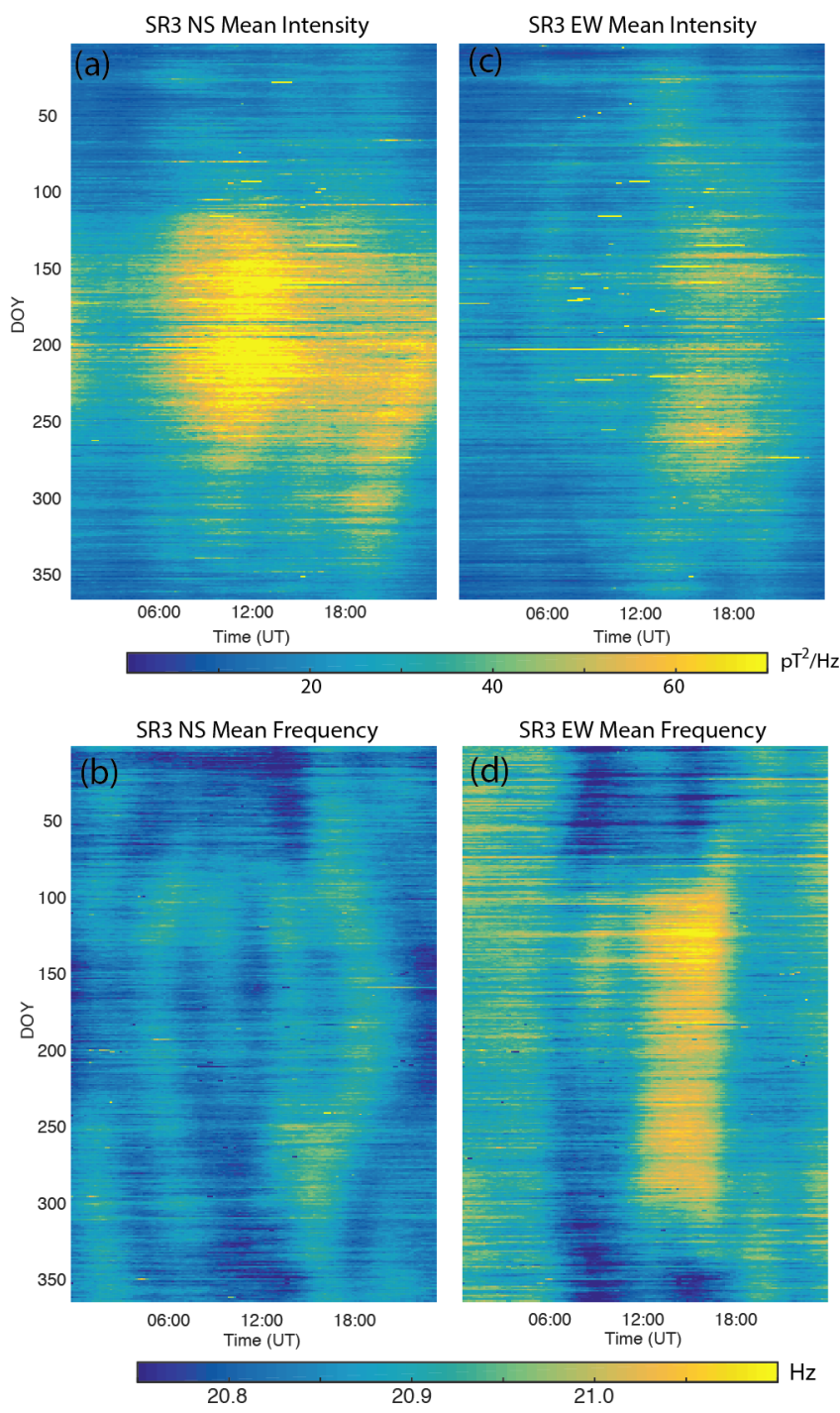

Figure 5. Time-Universal Time plots of the average of six years of the intensity and the peak frequency of the third Schumann resonance (SR3) from the north-south coil $(a, b)$ and the eastwest coil (c, d).

The patterns seen in the Time-UT intensity plot for the first SR match the expected modelled variation, for example as shown in Pechony et al. (2007) or Sátori et al. (2005). However, the Eskdalemuir data are much cleaner than Pechony et al. (2007) (see their Figure 8) and show the noticeable increase in thunderstorm activity during the summer (DOY 140-275), due to the longitude extent of the continents in the Northern Hemisphere, i.e. the west coast of the North America extends into the Pacific Ocean further than the west coast of South America does (Nickolaenko \& Hayakawa, 2014). We also compared our results to the annual plots of Time-UT variations in Ondrášková et al. (2007) for 20022005 from their system in Modra (Slovakia). As our plots are an average of the six available full calendar years and have a much higher UT time resolution in comparison to their Figure 7 (see in Ondrášková, A. et al., 2007), we can distinguish variations in each resonance in much finer detail.

Our frequency time-UT plots can be compared with the seasonally averaged features shown in Price \& Melnikov (2004) (their Figure 4) for the Mitzpe Ramon site (in Israel). The seasonal variations observed at both sites match well in the NS-orientated coil, for example showing the five peaks in frequency of the summer (JJA) period for the third resonance. The correlation is, however, poorer for the frequency parameters in the EW coils, particularly for the first resonance. The distance between Eskdalemuir and Mitzpe Ramon is relatively large, around 4Mm, with the Israeli site being further south and east of the UK and 
hence closer to the lightning centres of Indonesia and Africa. Price \& Melnikov (2004) note a clear minimum in the frequency variations in their EW coil when the African source activity peaks at 16:00 UT. In contrast, at Eskdalemuir we typically observe a peak in frequency at this time. This is consistent with the propagation function of the magnetic field (e.g. Nickolaenko and Hayakawa, 2002) where Mitzpe Ramon lies in a 'trough' and Eskdalemuir on a 'peak'.

Finally, we comment that the dawn terminator line is only clearly observed in the intensity and frequency of the first SR in the east-west coil. This is in contrast to Melnikov et al. (2004) and Ondrášková et al. (2007) who show clearer dawn and dusk terminators (though in the electric rather than magnetic fields in the case of Melnikov et al. (2004)). The indistinct terminator may relate to the higher latitude location of Eskdalemuir where twilight is much longer than in mid-latitudes (Sátori et al., 2007).

\section{CONCLUSION}

We present a series of data analyses from seven years of magnetic data at the Eskdalemuir observatory in the Scottish Borders of the UK. Eskdalemuir is a magnetically clean site and allows very small variations $(<0.1 \mathrm{pT})$ in the ELF band to be detected. We investigate the variation intensity and frequency parameters of the first three Schumann resonances in terms of the daily, monthly and annual variations. We find the well-known diurnal signals, along with the longer-term seasonal signals consistent with other studies. We also note changes in seasonal intensity of each resonance along with long term variation related to the solar cycle. There is also a decline in the peak frequencies of all three resonances over 2013 to 2019, which follow the descending phase of the current solar cycle. We have compared the results to published data from other sites and find good agreement. We intend to continue collecting ELF magnetic data at Eskdalemuir and to extend the record over a full solar cycle.

\section{ACKNOWLEDGMENTS}

We wish to acknowledge the help of Tony Swan, Tim Taylor and the BGS geomagnetism engineering team who assist with the maintenance of the instrumentation. We also thank Earle Williams and Tamas Bozoki for their thorough and helpful reviews of the initial manuscript submission. The sunspot number is available from SILSO (www.dics.be/silso/datafiles). The F10.7 index is available from Space Physics Data facility (omniweb.gsfc.nasa.gov). Eskdalemuir Induction Coil data can be downloaded from:

http://www.bgs.ac.uk/services/NGDC/citedData/catalogue.html.

This paper is published with the permission of the Executive Director, British Geological Survey (UKRI).

\section{REFERENCES}

Anyamba, E., Williams, E., Susskind, J., Fraser-Smith, A., and Fullekrug, M.: 2000, J. Atmos. Sci., 57, 1029. doi:10.1175/1520-0469(2000)057<1029:TMOTMJ>2.0.CO;2

Balser, M., and Wagner, C. A.: 1960, Nature, 188, 638. doi:10.1038/188638a0

Beggan, C. D. and Musur, M.A..: 2018, J. Geophy. Res., 123, 4202. doi:10.1029/2018JA025264

Beggan, C.D. and Musur, M.A.: 2019, J. Atmos. Sol. Terr. Phys., 190, 108. doi:10.1016/j.jastp.2019.05.009

Christian, H.J., Blakeslee, R.J., Boccippio, D.J., Boeck, W.L., Buechler, D.E., Driscoll, K.T., Goodman, S.J., Hall, J.M., Koshak, W.J., Mach, D.M. and Stewart, M.F.: 2003, J. Geophys. Res., 108, 4005, doi:10.1029/2002JD002347

De, S. S., De, B. K., Bandyopadhyay, B., Paul, S., Haldar, D. K. and Barui, S.: 2010, J. Atmos. Sol. Terr. Phys., 72, 829. doi:10.1016/j.jastp.2010.04.004

Füllekrug, M.: 1995, J. Atmos. Terr. Phys., 57, 479, doi:10.1016/0021-9169(94)00075-Y

Füllekrug, M., and Fraser-Smith, A. C.: 1996, Geophys. Res. Lett., 23, 2773. doi:10.1029/96GL02612

Füllekrug, M., Fraser-Smith, A. C., and Schlegel, K.: 2002, Europhys. Lett., 59, 626. doi:10.1209/epl/i2002-00150-y
Greenberg, E., and Price, C.: 2007, Radio Sci., 42, doi:10.1029/2006RS003477

Kułak, A., Kubisz, J., Michalec, A., Zięba, S., and Nieckarz, Z.: 2003, J. Geophys. Res., 108, 1. doi:10.1029/2002JA009305

Melnikov, A., Price, C., Sátori, G., and Füllekrug, M.: 2004, J. Atmos. Sol.-Terr. $\quad$ Phys. 1187. doi:10.1016/j.jastp.2005.05.014.

Nickolaenko, A.P. and Hayakawa, M.: 2002, Resonances in the Earth-lonosphere Cavity, vol. 19. Springer Science \& Business Media.

Nickolaenko, A.P. and Hayakawa, M.: 2014, Schumann Resonance for Tyros (Essentials of Global Electromagnetic Resonance in the Earth-lonosphere Cavity), Springer, Springer Geophysics Series XI, Tokyo

Nickolaenko, A. P., Koloskov, A. V, Hayakawa, M., Yampolski, Y. M., Budanov, O. V, and Korepanov, V. E.: 2015, Sun and Geosphere, 10, 39.

Nieckarz, Z., Zięba, S., Kułak, A., and Michalec, A.: 2009, Monthly Weather Rev. 137, 4401. doi:10.1175/2009MWR2920.1

Ondrášková, A., Kostecký, P., Ševčík, S., and Rosenberg, L.: 2007, Radio Sci., 42. doi: 10.1029/2006RS003478

Ondrášková, A., Ševčík, S., and Kostecký, P.: 2011, J. Atmos. Sol. Terr. Phys., 73, 534. doi:10.1016/j.jastp.2010.11.013

Pechony, O., Price, C. and Nickolaenko, A.P.: 2007, Radio Sci., 42, RS2S06, doi:10.1029/2006RS003456.

Price, C. and Melnikov, A.: 2004, J. Atmos. Sol. Terr. Phys., 66, 1179, doi:10.1016/j.jastp.2004.05.004.

Sátori, G.: 1996. J. Atmos. Sol. Terr. Phys., 58, 1483. doi: 10.1016/0021-9169(95)00146-8

Sátori, G., Williams, E., and Mushtak, V.: 2005, J. Atmos. Sol.Terr. Phys. 67, 553. doi:10.1016/j.jastp.2004.12.006.

Sátori, G., Neska, M., Williams E. and Szendrői, J.: 2007, Radio Sci., 42, 1. doi:10.1029/2006RS003483

Sátori, G., Williams, E., Price, C., Boldi, R., Koloskov, A., Yampolski, Y., Guha, A. and Barta, V.: 2016, Surv. Geophys., 37, 757. doi:10.1007/s10712-016-9369-z

Schumann, W. O.: 1952, Z. Naturforsch., 7, 149. doi:10.1515/zna1952-0202

Welch, P. D.: 1967, IEEE Trans. Audio Electroacoustics, 15, 70. doi:10.1109/TAU.1967.1161901

Williams, E. R.: 1992, Science, 256, 1184. doi: $10.1126 /$ science. 256.5060 .1184

Williams. E.R.: 2016, Sun and Geosphere, 11, 75.

Williams, E., K. Rothkin, D. Stevenson, and Boccippio, D.: 2000, J. Appl. Meteor., 39, 2223. doi:10.1175/15200450(2001)040<2223:GLVCBC>2.0.CO;2

Williams, E. R., and Sátori, G.: 2007, Radio Sci., 42. doi:10.1029/2006RS003494

Williams, E., Guha, A., Boldi, R., Christian, H. and Buechler, D.: 2019, J. Atmos. Sol.-Terr. Phys, 189, 27. doi:10.1016/j.jastp.2019.03.011.

Zieger, B., and Sátori, G.: 1999, 11th International Conference on Atmospheric Electricity, 701. NASA Conf. Publ. 